\title{
Effect of Different Pre-Germination Treatments on Germination and Early Growth of Balanites aegyptiaca Seeds in Northern Guinea Savanna Agrological Zone, Nigeria
}

\author{
Dahunsi, O. M. ${ }^{1}$, Baba, G. O. ${ }^{1}$, Olaifa, R. K. ${ }^{1}$, Erhabor, T. A ${ }^{2}$, Sodimu, A. I ${ }^{1 *}$ \\ ${ }^{1}$ Savanna Forestry Research Station, Forestry Research Institute of Nigeria, PMB 1039, Samaru, Zaria Nigeria \\ ${ }^{2}$ Federal College of Forestry, Forestry Research Institute of Nigeria, Jos, Plateaus State, Nigeria
}

\section{*Corresponding Author}

Sodimu, A. I

\author{
Article History \\ Received: 16.10 .2020 \\ Accepted: 03.11.2020 \\ Published: 17.11.2020
}

\begin{abstract}
Study was conducted at Savanna Forestry Research Station Samaru, Zaria to evaluate effect of different pre-germination treatments on the germination and early growth of Balanites aegyptiaca seeds. The treatments includes partial cracking of seed, partial burning of seed, removal of seed coat, soaking in boiling water and untreated control. The experiments was laid out in a completely randomized design with five replication. The results of the germination test shows significantly $(\mathrm{P} \leq 0.05)$ higher germination percentage among all treatments. Partially cracked seed recorded highest $(67.3 \%)$ germination and seed with removed seed coat $(45.6 \%)$ had the lowest germination among all the pregermination treatments, while untreated control $(9.6 \%)$ recorded the least germination. There were no significant $(\mathrm{P} \geq 0.05)$ difference in the growth of $B$. aegyptiaca seedling among pre-germination treatments, although partially cracked seed $(5.81 \mathrm{~cm}$ and 7.40$)$ recorded the highest seedling height and number of leaves, while seed with removed seed coat $(5.61 \mathrm{~cm}$ and 6.87$)$ had the lowest seedling height and number of leaves respectively. The control $(0.71 \mathrm{~cm}$ and 0.71 ) recorded the least seedling height and number of leaves during the study period. The above findings has shown the potential of all the pre-germination treatments especially partial cracking of seed coat as most effective mechanism to break the dormancy of the seed in order to initiate germination and growth for efficient plantation establishment.
\end{abstract}

Keywords: Germination, Efficient, Plantation Establishment, Guinea Savanna, Treatment.

\section{INTRODUCTION}

Balanites aegyptiaca is a species classified as a member of Zygophyllaceae. This tree is native to mainly Africa and parts of Middle East. It is called Desert date, soap berry tree, Thorn tree, and in Egypt, it is called Egyptian Myrobalan and Egyptian balsam. While in Hausa it is called Aduwa, in Tuareg language it is called Taboraq, in Swahili Mchunju while it is called Bedena in Amharic [1]. The species is found in the Sahel-Savannah region across Africa, and can tolerate wide range of soil types. The tree reaches $10 \mathrm{~m}(33 \mathrm{ft})$ in height with a generally narrow form. The branches have long, straight green spines arranged in spirals. The dark green compound leaves grow out of the base of the spines and are made up of two leaflets which are variable in size and shape. The fluted trunk has grayish brown, ragged-bark with yellow-green patches where it is shed [1]. The plant is well known for its multipurpose medicinal uses, and rich in steroidal saponins that produced diosgenin, which is a source of steroidal drugs such as corticosteroids, contraceptives and sex hormones [2].

However, due to excessive exploitation for a variety of purposes, this species falls in the category of endangered plant species [3]. Effective propagation and seedling establishment are the basic requirements for sustainable management of rare species. Seed germination and seedling establishment at early stage of plant cycle are most prone to environmental disturbance which may result to high mortality rates [4]. Difficulty may occur in viable seed germination even under favorable environmental condition due to hard seed coat. According to [5], seed germination is influence by type of substrate used and environmental factors such as oxygen, water, temperature and for some species may be

Copyright (C) 2020 The Author(s): This is an open-access article distributed under the terms of the Creative Commons Attribution 4.0 International License (CC BY-NC 4.0) which permits unrestricted use, distribution, and reproduction in any medium for non-commercial use provided the original author and source are credited. 
affected by light. Adelani [6] employed hydro priming method for rapid and uniform germination of seed by controlling inhibition to an extent where germination will be initiated. With all the above mention and other reasons, there is need for a simple, non-harmful and non-chemical methods to break dormancy of the plant. This will give room for easy adoption and promote plantation establishment to conserve the tree species from going into extinction. Hence, the present study attempt to investigate effect of different pre germination treatments on the germination and growth of B. aegyptiaca seeds to enhance plantation establishment.

\section{Materials ANd Methods \\ Study Area}

The study was carried out at Savanna Forestry Research Station Nursery, Samaru $\left(11^{0} 11^{\prime \prime} \mathrm{N}, 07^{0} 38^{\prime \prime} \mathrm{E}\right.$ and $686 \mathrm{~m}$ above sea level) Zaria.

\section{Treatments and Experimental Design}

The treatments consisted of four pre-germination methods (partial burning of seed coat, partial cracking of seed coat, removal of seed coat and soaking in boiling water) and untreated control resulting in a total of five treatments. The five treatments were replicated five times in a completely randomized design with 9 seeds per replicate which resulted in a total of 45 seeds per treatment. A total of 225 seeds were used for the whole experiment.

\section{Sowing of Seeds}

Bulk soil from nursery site were taken and sieved to remove plant debris. Twenty five germination boxes $90 \mathrm{~cm}$ $\mathrm{x} 45 \mathrm{~cm}$ x $30 \mathrm{~cm}$ were filled with nursery soil. Forty five seeds each of pre-treated seeds and control were divided into five groups of 9 seeds each per group, and were sown in germination boxes, and were thoroughly watered every other day and kept for a period of eight weeks.

\section{Data Collection and Analysis}

Data collected includes number of germinated seeds per each replicates, and these were recorded at 2 days interval 10days after sowing for 27days, while data on plant height and number of leaves per seedling were obtained from five randomly selected seedlings per replicates, and these were recorded at 2 weeks interval for 8 weeks. Germination percentage was computed using the formula below.

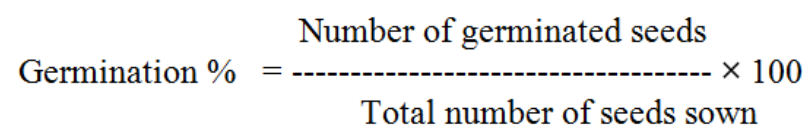

Data on germination percentage were then transformed using arcsine transformation, while square root transformation was used to transformed data on plant height and number of leaves per seedling. The different formulae are as follow:

Where,

$$
\text { SQRT: } Y^{\prime}=\sqrt{ }(\mathbf{Y}+\mathbf{0 . 5})
$$

$\mathbf{Y}=$ Original data to be transformed.

$\mathbf{0 . 5}=$ A constant.

$\mathbf{Y}^{\prime}=$ Transformed data (Steel and Torrie, 1960).

\section{Arcsine: $\mathbf{Y}^{\prime}=\arcsin \sqrt{ }(\mathbf{Y})$}

$\mathbf{Y}^{\prime}=$ Transformed value.

$\mathbf{Y}=$ Original value in decimal format [7].

All transformed data were subjected to analysis of variance (ANOVA) using SAS software package (version 9.0). Mean differences among treatment were separated using Least Significant Difference (LSD) at $P=0.05$

\section{RESUlTS AND DisCUSSION}

The results of effect of different pre-germination treatments on the germination and growth of B. aegyptiaca seeds and seedlings are discussed below.

\section{Effect of Pre-germination treatments on seed germination of Balanites aegyptiaca at Bomo, Zaria}

There was significant difference $(\mathrm{P} \leq 0.01)$ in germination of $B$. aegyptiaca seeds subjected to the different pregermination treatments, and these generally ranges from $9.6 \%$ to $67.3 \%$ from 11 days to 27 days post treatment periods (table 3.1 and figure 3.1). Partially cracked seeds recorded significantly $(\mathrm{P} \leq 0.05)$ higher germination percentage 11days 
to 27 days (43.1\% to $67.3 \%$ ) post germination periods than other treatments and control. At 11days post treatment, similar $(\mathrm{P} \geq 0.05)$ germination were recorded from other treatments and control. However, at 13days and 15days post treatment periods, similar $(\mathrm{P} \geq 0.05)$ germination $(15.5 \%$ to $26.4 \%)$ were recorded on seeds soaked in boiling water, partially burn seed and those with removed seed coat, and they were significantly $(\mathrm{P} \leq 0.05)$ higher in germination than control treatment which recorded lowest germination (9.6\%). At 17days and 19days post treatment periods, seeds soaked in boiling water recorded significantly $(\mathrm{P} \leq 0.05)$ higher germination $(45.6 \%$ and $51.1 \%)$ than other treatments. This was followed by partially burn seed $(32.4 \%$ and $44.4 \%)$ which was also significantly $(\mathrm{P} \leq 0.05)$ higher in germination than removed seed coat $(21.2 \%$ and $32.3 \%)$ which also recorded significantly $(\mathrm{P} \leq 0.05)$ higher germination than control $(9.6 \%)$ which recorded least germination. The germination recorded from 21 days to 27 days post treatment periods on seeds soaked in boiling water and those with partially burn coat were not significantly $(\mathrm{P} \geq 0.05)$ different, and this ranges from $48.2 \%$ to $60.7 \%$, but significantly $(\mathrm{P} \leq 0.05)$ higher than seeds with removed seed coat $(35.2 \%$ to $45.6 \%)$ which also recorded significantly $(\mathrm{P} \leq 0.05)$ higher germination than control $(9.6 \%)$ during the periods.

The highest germination percentage obtained from this study from partially cracked seed followed by seeds soaked in boiling water can be attributed to the softness of the seed coat hence better permeability of seed coat to water and gases. This finding was in agreement with report of Olujobi et al., [8] that soaking of Afzelia africana in cold water for 48 hours resulted in increased rate of germination. The result also corroborates the finding of Owonubi et al., [9] who asserted that soaking of Azadirachta indica seed for a long period in water increase the germination percentage. However, this result disagrees with the finding of Otegbeye and Momodu [10] that over soaking of Parkia biglobosa seeds in water may reduce germination percentage through oxygen deficiency.

Table-1: Effect of Pre-germination treatments on seed germination of Balanites aegyptiaca at Bomo, Zaria

\begin{tabular}{|l|l|l|l|l|l|l|l|l|l|}
\hline & \multicolumn{9}{|l|}{ Mean Germination rate (\%) } \\
\hline & \multicolumn{7}{|l}{ Sampling period (days) } \\
\hline Treatments & 11 & 13 & 15 & 17 & 19 & 21 & 23 & 25 & 27 \\
\hline Burning of seed coat & $9.6 \mathrm{~b}$ & $15.5 \mathrm{bc}$ & $22.9 \mathrm{~b}$ & $32.4 \mathrm{c}$ & $44.4 \mathrm{c}$ & $48.2 \mathrm{~b}$ & $54.0 \mathrm{~b}$ & $56.1 \mathrm{~b}$ & $60.7 \mathrm{~b}$ \\
\hline Cracking of seed coat & $43.1 \mathrm{a}$ & $46.9 \mathrm{a}$ & $54.1 \mathrm{a}$ & $60.5 \mathrm{a}$ & $65.3 \mathrm{a}$ & $65.3 \mathrm{a}$ & $67.1 \mathrm{a}$ & $67.1 \mathrm{a}$ & $67.3 \mathrm{a}$ \\
\hline Removal of seed coat & $13.6 \mathrm{~b}$ & $17.5 \mathrm{~b}$ & $21.2 \mathrm{~b}$ & $21.2 \mathrm{~d}$ & $32.3 \mathrm{~d}$ & $35.2 \mathrm{c}$ & $39.2 \mathrm{c}$ & $43.2 \mathrm{c}$ & $45.6 \mathrm{c}$ \\
\hline Soaking in hot water & $13.6 \mathrm{~b}$ & $17.5 \mathrm{~b}$ & $26.4 \mathrm{~b}$ & $45.6 \mathrm{~b}$ & $51.1 \mathrm{~b}$ & $53.5 \mathrm{~b}$ & $56.1 \mathrm{~b}$ & $56.3 \mathrm{~b}$ & $58.0 \mathrm{~b}$ \\
\hline Control & $9.6 \mathrm{~b}$ & $9.6 \mathrm{c}$ & $9.6 \mathrm{c}$ & $9.6 \mathrm{e}$ & $9.6 \mathrm{e}$ & $9.6 \mathrm{~d}$ & $9.6 \mathrm{~d}$ & $9.6 \mathrm{~d}$ & $9.6 \mathrm{~d}$ \\
\hline SED \pm & 2.651 & 3.342 & 4.302 & 2.059 & 2.897 & 4.509 & 3.330 & 3.853 & 4.187 \\
\hline LSD & 5.530 & 6.971 & 8.975 & 4.295 & 6.043 & 9.406 & 6.947 & 8.036 & 8.735 \\
\hline Significance & $* *$ & $* *$ & $* *$ & $* *$ & $* *$ & $* *$ & $* *$ & $* *$ & $* *$ \\
\hline Mean & 17.9 & 21.4 & 26.9 & 36.9 & 41.0 & 41.9 & 45.2 & 46.5 & 48.3 \\
\hline CV $(\%)$ & 23.5 & 24.7 & 25.3 & 9.6 & 11.2 & 17.0 & 11.7 & 13.1 & 13.7 \\
\hline
\end{tabular}

Means followed by same letter(s) in the same column are not different statistically at $P=0.05$ using LSD $* *=$ Significant at $(\mathrm{P} \leq 0.01)$

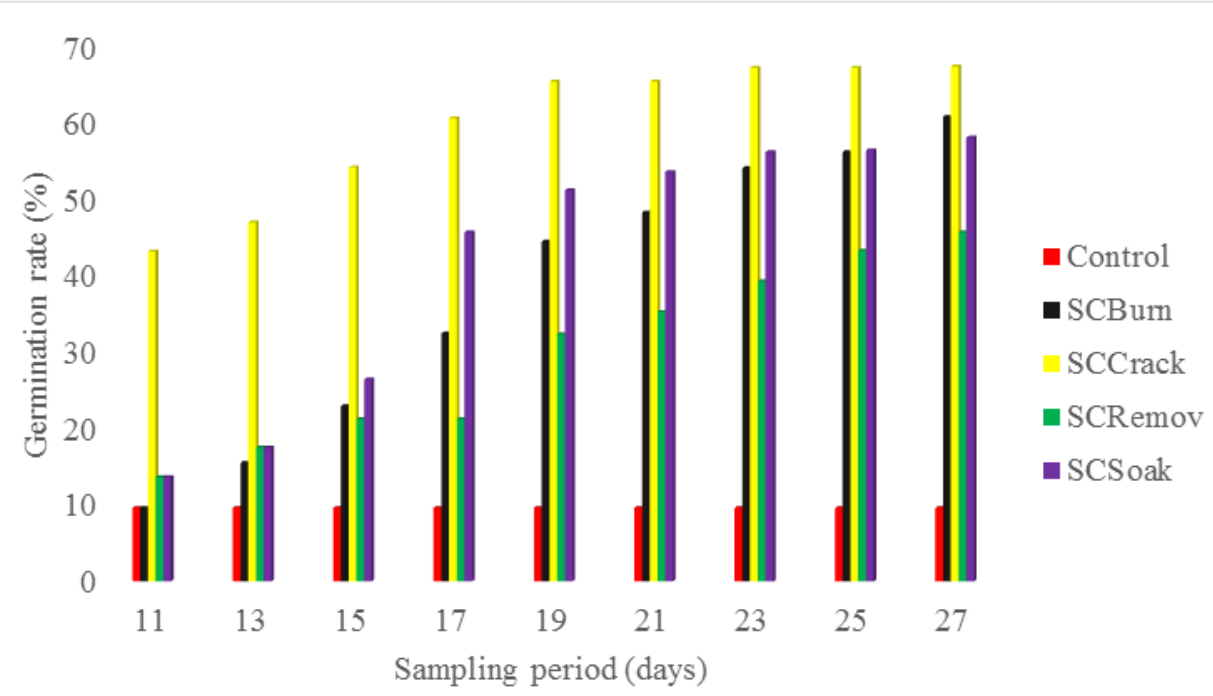

Fig-1: Effect of pre-germination treatments on germination of Balanytes aegyptica seed at 2 weeks interval post treatment periods 


\section{Effect of Pre-germination treatments on plant height of Balanites aegyptiaca seedlings at Bomo, Zaria}

Significantly $(\mathrm{P} \leq 0.01)$ higher plant height of $B$. aegyptiaca seedlings subjected to different pre-germination treatments were recorded at 2 weeks to 8 weeks post treatment periods (Table-2 and Figure-3), and it range from $0.71 \mathrm{~cm}$ to $6.01 \mathrm{~cm}$ respectively. The highest seedling height was recorded on partially cracked seed from 2 weeks to 8 weeks $(5.64 \mathrm{~cm}$ to $6.01 \mathrm{~cm})$ followed by those with burnt seed coat $(5.55 \mathrm{~cm}$ to $5.90 \mathrm{~cm})$, seed soaked in boiling water $(5.46 \mathrm{~cm}$ to $5.85 \mathrm{~cm})$, seed with removed coat $(5.50 \mathrm{~cm}$ to $5.77 \mathrm{~cm})$, and control treatment recorded the lowest seedling height $(0.71 \mathrm{~cm})$ throughout the sampling periods. The cumulative average heights of seedlings with pre-germination treatments were found to be similar $(\mathrm{P}>0.05)$ with seedling resulting from partially cracked seed coat $(5.81 \mathrm{~cm})$ having the highest cumulative average followed by seedling with burnt seed coat $(5.66 \mathrm{~cm})$, seedling from soaked seed $(5.63 \mathrm{~cm})$ and seedling from seeds with removed coat $(5.61 \mathrm{~cm})$. The cumulative average height of the control was found to be $0.71 \mathrm{~cm}$, and was significantly $(\mathrm{P} \leq 0.05)$ lower than seedling heights of all the pre-germination treatments. Hence the various pregermination treatment had varying but similar seedling heights which were different from control. Therefore, it can be deduce that the four different pre-germination treatments has no effect on seedling height of B. aegyptiaca. Olujobi and Dahunsi [11] affirmed that there was difference in growth rate on the comparative effect of different potting mixture on the early growth of Afzelia africana. In contrast, Samia et al., [12] observed that there was improved growth of scratched baobab seeds soaked in sulphuric acid for either 30 or $60 \mathrm{~min}$.

Table-2: Effect of Pre-germination treatments on plant height of Balanites aegyptiaca seedling at Bomo, Zaria

\begin{tabular}{|l|l|l|l|l|}
\hline & \multicolumn{4}{|c|}{ Mean Plant Height per seedling $(\mathrm{cm})$} \\
\hline Treatments & $2 \mathrm{wks}$ & $4 \mathrm{wks}$ & $6 \mathrm{wks}$ & $8 \mathrm{wks}$ \\
\hline Burning of seed coat & $5.55 \mathrm{a}$ & $5.47 \mathrm{a}$ & $5.71 \mathrm{a}$ & $5.90 \mathrm{a}$ \\
\hline Cracking of seed coat & $5.64 \mathrm{a}$ & $5.73 \mathrm{a}$ & $5.86 \mathrm{a}$ & $6.01 \mathrm{a}$ \\
\hline Removal of seed coat & $5.50 \mathrm{a}$ & $5.53 \mathrm{a}$ & $5.63 \mathrm{a}$ & $5.77 \mathrm{a}$ \\
\hline Soaking in boiling water & $5.46 \mathrm{a}$ & $5.50 \mathrm{a}$ & $5.70 \mathrm{a}$ & $5.85 \mathrm{a}$ \\
\hline Control & $0.71 \mathrm{~b}$ & $0.71 \mathrm{~b}$ & $0.71 \mathrm{~b}$ & $0.71 \mathrm{~b}$ \\
\hline SED \pm & 0.140 & 0.126 & 0.142 & 0.133 \\
\hline LSD & 0.2922 & 0.2635 & 0.2962 & 0.2783 \\
\hline Significance & $* *$ & $* *$ & $* *$ & $* *$ \\
\hline Mean & 4.57 & 4.59 & 4.72 & 4.85 \\
\hline CV $(\%)$ & 4.84 & 4.35 & 4.76 & 4.35 \\
\hline
\end{tabular}

Means followed by same letter(s) in the same column are statistically similar at $P=0.05$ using LSD $* *=$ Significant at $(\mathrm{P} \leq 0.01)$

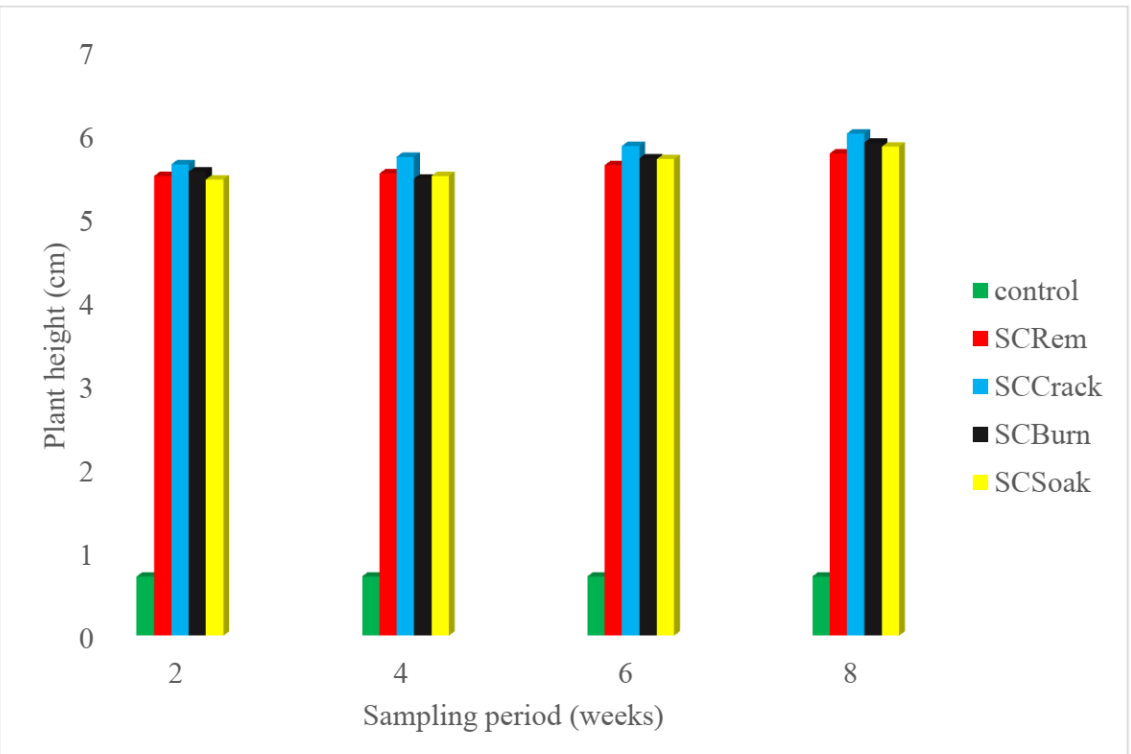

Fig-2: Effect of pre-germination treatments on plant height of Balanites aegyptiaca seedlings at 2, 4, 6 and 8weeks post treatment periods

\section{Effect of Pre-germination treatments on number of leaves of Balanites aegyptiaca seedlings at Bomo, Zaria}

Highly $(\mathrm{P} \leq 0.01)$ significant number of leaves at 2 weeks to 8 weeks were obtained from different pre-germination treatments on B. aegyptiaca seeds (Table-3 and Figure-3). At 2 weeks, number of leaves obtained from seed soaked in boiling water (7.20), partially burnt seed (7.16) and partially cracked seed (7.13) were similar $(\mathrm{P} \geq 0.05)$, but significantly $(\mathrm{P} \leq 0.05)$ different from seed with removed seed coat (6.76) and control (0.71). Similarly, seeds with removed seed coat 
(6.76) had significantly $(\mathrm{P} \leq 0.05)$ higher number of leaves than control $(0.71)$ having lowest number of leaves. At 4weeks, similar trend was observed with partially burnt seeds (7.30), seeds soaked in boiling water (7.24) and partially cracked seeds (7.20) having similar $(\mathrm{P} \geq 0.05)$ number of leaves which were significantly $(\mathrm{P} \leq 0.05)$ higher than seed with removed coat $(6.83)$ and control $(0.71)$. Seeds with removed coat $(6.83)$ also recorded significantly $(\mathrm{P} \leq 0.05)$ higher number of leaves than control $(0.71)$ which recorded the lowest leaves. However, no significant $(\mathrm{P} \geq 0.05)$ differences in number of leaves was recorded at 6 weeks and 8 weeks from all treatments except for control $(0.71)$ which recorded significantly $(\mathrm{P} \leq 0.05)$ lower number of leaves. The cumulative leaf average number for all pre-germination treatments were found to be similar $(\mathrm{P}>0.05)$ with partially cracked seed (7.40) having highest cumulative average followed by seed soaked in boiling water (7.32), partially burnt seed (7.30), removed seed coat (6.87) and control (0.71) which was significantly $(\mathrm{P} \leq 0.05)$ lower than number of leaves of all pre-germination treatments. This suggest that all the pregermination treatments had similar effect on number of leaves of B. aegyptiaca seedling. This disagreed with finding of Shakeel [13], who observed an increased in growth of Cyamopsis tetragonolobust seed due to influence of coconut water.

Table-3: Effect of Pre-germination treatments on number of leaves of Balanites aegyptiaca seedling at Bomo,

Zaria

\begin{tabular}{|l|l|l|l|l|}
\hline & \multicolumn{4}{|l|}{ Mean Number of Leaves per seedling } \\
\hline Treatments & $2 \mathrm{wks}$ & $4 \mathrm{wks}$ & $6 \mathrm{wks}$ & $8 \mathrm{wks}$ \\
\hline Burning of seed coat & $7.16 \mathrm{a}$ & $7.30 \mathrm{a}$ & $7.53 \mathrm{a}$ & $7.57 \mathrm{a}$ \\
\hline Cracking of seed coat & $7.13 \mathrm{a}$ & $7.20 \mathrm{a}$ & $7.31 \mathrm{a}$ & $7.51 \mathrm{a}$ \\
\hline Removal of seed coat & $6.76 \mathrm{~b}$ & $6.83 \mathrm{~b}$ & $6.92 \mathrm{a}$ & $6.98 \mathrm{a}$ \\
\hline Soaking in boiling water & $7.20 \mathrm{a}$ & $7.24 \mathrm{a}$ & $7.45 \mathrm{a}$ & $7.46 \mathrm{a}$ \\
\hline Control & $0.71 \mathrm{c}$ & $0.71 \mathrm{c}$ & $0.71 \mathrm{~b}$ & $0.71 \mathrm{~b}$ \\
\hline SED \pm & 0.225 & 0.208 & 0.238 & 0.234 \\
\hline LSD & 0.4696 & 0.4329 & 0.4958 & 0.4883 \\
\hline Significance & $* *$ & $* *$ & $* *$ & $* *$ \\
\hline Mean & 5.83 & 5.88 & 5.95 & 6.02 \\
\hline CV $(\%)$ & 6.10 & 5.58 & 6.32 & 6.15 \\
\hline
\end{tabular}

Means followed by same letter(s) in the same column are not different statistically at $P=0.05$ using LSD $* *=$ Significant at $(\mathrm{P} \leq 0.01)$
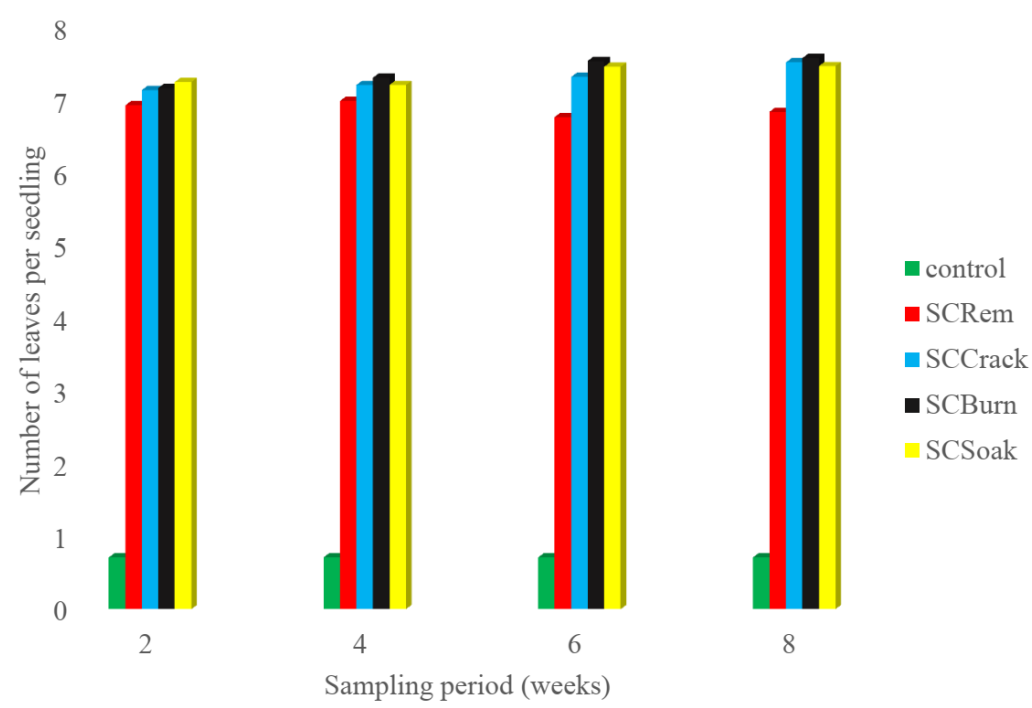

Fig-3: Effect of pre-germination treatments on number of leaves of Balanites aegyptiaca seedlings at 2, 4, 6 and 8weeks post treatment periods

\section{Conclusion}

The seed dormancy of Balanites aegyptiaca is mainly due to hard seed coat, which affect the seed germination. Results obtain from this study emphasized the necessity of breaking Balanites aegyptiaca hard seed coat before sowing. However different pre germination treatment understudy does not affect the growth height and number of leaves of Balanites aegyptiaca. It is hope that the result of this study will provide useful information for large scale plantation development and encourage domestication of Balanites aegyptiaca. 


\section{RECOMMENDATION}

Based on the results above it is recommended that for easy multiplication of seedlings of Balanites aegyptiaca for plantation establishment in Northern Guinea Savanna Agrological Zone nursery workers should adopt partial cracking Method of the seed coat to enhance better germination of the seed.

\section{REFERENCE}

1. Delile. A. (2016). Balanites Genus: U. S National plant Germination System. Handbook on seedling Evaluation, $3^{\text {rd }}$ edition.

2. Farid, H. E., Hastinger, O., Kunert, C. W., \& Hnburger, M. (2002). New Steroidal glycosides from Balanities aegyptiaca Helvet Chim. 88: 1019-1026.

3. Elfeel, A. A. (2012). Effect of seed pre-treatment and sowing orientation on germination of Balanitis aegyptiaca seeds. Journal of Agriculture Environmental Science, 12:897-900.

4. Moles, A. T., \& Westly, M. (2004). What do seedling die from and what are the implication for evolution of seed size? Oikos, 106: 193-199.

5. Hartmann, H. T., \& Kester, D. E. (1993). Plant propagation; principle and practice. Hall inc; Inglewood cliffs; NJ; 662.

6. Adelani, D. O., Suleiman, R., \& Apene, E. (2019). Effect of Period of Hydro-priming and Seed weights on the germination of Vitex doniana sweet seeds. Journal of Research in Forestry, Wildlife and Environment, 11(3):185-1

7. Steel, R. G. D., \& Torrie, J. H. (1960). Principles and procedures of statistics with special reference to the Biological Sciences. McGraw-Hill book company Inc. New York, USA. 481.

8. Olujobi, O. J., Olayode, O. O., \& Dahunsi, O. M. (2010). Breaking of seed dormancy of Afzelia africana towards plantation establishment for sustainable production. Proceeding of the $33^{\text {rd }}$ Annual conference of the Forestry Association of Nigeria (FAN) held in Benin City, Edo State, Nigeria. Pp 205-212

9. Owonubi, J. J., Otegbeye, G. O., \& Nwokedi, C. I. (2005). Development of pre-germination technique for Azadirachta indica; Preliminary investigation. Proceeding of Annual conference of Forestry association of Nigeria, 7 th $-11^{\text {th }}$ Nov. 2005. 497-505.

10. Otegbeye, G. O. and Momodu. A. B. (2002). Preliminary study of germination technique for seed of Parkia biglobosa. Journal of Agriculture and Environment, 3(2): 405-409.

11. Olujobi, O. J., \& Dahunsi, O. M. (2009). Comparative effect of potting soils from different sources on early growth of Afzelia africana seedling. Journal of Researches in Agricultural Sciences, 2(1\&2): 82-86

12. Samia, M. Z., Bagly, E. L., \& Nahed, M. R. (2018). Influence of pregermination treatment on overcoming seed dormancy and growth of Baobab. Journal of Production Science, 45(2): 465-476.

13. Shakeel, A (2010). Effect of coconut water on Callus growth of Cyamopsis tetragonolobust. Pharmacia, 1(1): 2532. 